\title{
ВОССТАНОВИТЕЛЬНЫЙ РЕМОНТ ШПИНДЕЛЬНЫХ УЗЛОВ В КОМПАНИИ SKF
}

Ключевые слова: шпиндельный узел, точностные характеристики станка, ППР, «вибрационная подпись» ШУ

\section{Игорь САФОНОВ, Алексей БАННИКОВ}

Представлен методологический подход к ремонту шпиндельных узлов (ШУ), реализуемый компанией SKF на базе инжиниринговых центров SKF Solution Factory по всему миру. Приведены основные причины возникновения неисправностей ШУ и регламент их устранения.

\section{ВВЕДЕНИЕ}

Одним из ключевых факторов эффективной работы предприятий является готовность парка ответственного производственного оборудования. В случае станков, готовность прежде всего определяется возможностью выпуска продукции с требуемыми точностными характеристиками. В связи с этим, к современным металлообрабатывающим станкам предъявляются высокие требования, касающиеся надежности и точности работы, а также техникоэксплуатационным параметрам. Шпиндельный узел является одним из основных компонентов, определяющих точностные характеристики станка и скорость обработки. Нарушение требований по эксплуатации, недостаточный уровень компетентности рабочего персонала, а также несвоевременное и некорректное техническое обслуживание влияет на качество и точность обработки заготовки, значительно сокращает эксплуатационный срок службы ШУ, что особенно критично для серийного производства, где буквально каждый час простоя станка приносит ощутимые убытки для предприятия.

\section{ОСНОВНЫЕ НЕИСПРАВНОСТИ ШУ,}

\section{ВОЗНИКАЮЩИЕ В ПРОЦЕССЕ ЭКСПЛУАТАЦИИ}

В $80 \%$ случаев основной причиной выхода ШУ из строя является повреждение подшипников передней или задней опоры вала. Данный дефект проявляется нехарактерным шумом во время работы узла, повышенной вибрацией или температурой в зоне подшипниковых опор, а также заклиниванием. Причиной данных неисправностей, как правило, служит удар ШУ о заготовку или поворотный стол, несоблюдение паспортных требований производителя по техническому обслуживанию и эксплуатации или неисправность других систем станка, сопряженных с ШУ. Оставшиеся 20\% причин выхода ШУ из строя включают широкий спектр всевозможных дефектов, которые возникают вследствие некорректной эксплуатации ШУ, неотлаженной системы ППР на предприятии или наличия производственного брака в самом ШУ. Наиболее частыми причинами неисправностей, причисляемыми к данной группе, можно считать следующие: износ или деформация инструментального конуса, посадочных мест подшипников на валу или в корпусе, повреждение устройства фиксации инструмента, обмоток статора, датчиков или ротационного соединения.

Развитие дефекта происходит очень быстро, поэтому использование ШУ даже при проявлении незначительных дефектов может привести к более серьезным повреждениям и, как следствие, дорогостоящему и долговременному ремонту. Именно поэтому при выявлении первых признаков неисправностей рекомендуется выполнить демонтаж узла со станка и передать его в специализированный сервисный центр для проведения необходимых ремонтно-восстановительных работ.

\section{ВОССТАНОВЛЕНИЕ - РАБОТА ДЛЯ ПРОФЕССИОНАЛОВ}

Шпиндельный узел - это высокоточный и высокотехнологичный узел, для обслуживания которого требуются соответствующие компетенции и оборудование. Как правило, ремонт ШУ выполняется с целью полного восстановления паспортных характеристик узла. Одной из основных характеристик, определяющих точностные параметры ШУ, являет- 


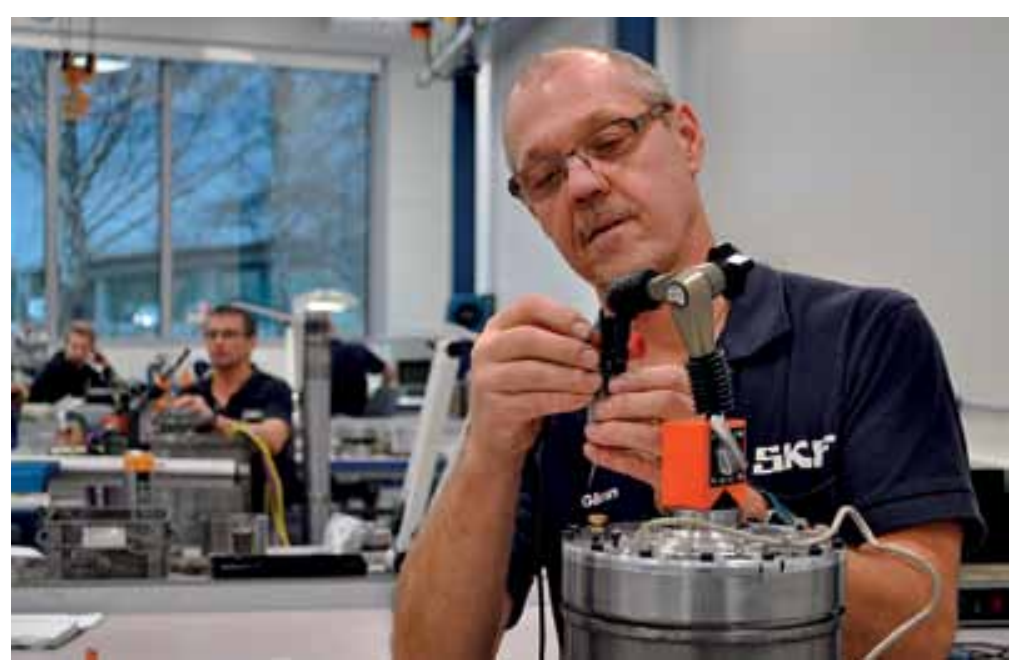

Puc. 1. Ремонт ШУ специалистом SKF

ся точность биения инструментального конуса, при этом в среднем значение этого параметра должно находиться в пределах от 2 до 5 мкм в зависимости от типа ШУ.

Для достижения таких точностных характеристик, работы по восстановлению ШУ необходимо проводить в соответствии с жесткими требованиями к квалификации персонала, а также чистоте и температурному режиму в помещении. В равной степени важно использование качественных запчастей и наличие определенного перечня высокоточного измерительного инструмента, а также специального оборудования, позволяющего выполнять как ремонтно-восстановительные работы, так и поэтапный контроль качества (рис. 1).

В свою очередь, выполнение ремонта с нарушением вышеуказанных требований может усугубить состояние узла. При этом некоторые компоненты, такие как вал с инструментальным конусом, система зажима инструмента, ротационные соединения и энкодерные кольца являются дорогостоящими, и в случае их повреждения стоимость ремонта значительно возрастает.

Важно учесть, что стоимость, срок ремонта и последующая эффективная эксплуатация ШУ также зависят от качества проведенных работ по демонтажу шпиндельного узла со станка. Корректное отключение узла и его извлечение из шпиндельной бабки требуют специальных навыков, без которых в процессе демонтажа возможны удары, повреждения присоединительных элементов и других частей шпинделя.
Не менее важен завершающий процесс монтажа шпиндельного узла обратно на станок и пусконаладочные работы. Правильная настройка и проверка всех систем и функций ШУ с помощью станка ЧПУ напрямую влияют на точностные параметры и производительность узла (рис. 2).

\section{ПОДХОД SКF К ВОССТАНОВЛЕНИЮ ШУ}

Процесс восстановления шпинделей основывается на многолетнем опыте компании SKF, полученном при производстве продукции и эксплуатации станков по всему миру и зарегистрированном в единой базе данных SSMS. Такой подход позволяет специалистам SKF из 18 инжиниринговых центров SKF Solution Factory, расположенных в разных странах мира, обмениваться опытом и получать доступ к уже опробованным и зарекомендовавшим себя решениям для конкретных типов и моделей ШУ..

Процедура ремонта SKF, включающая технические стандарты с соответствующими критериями допустимости всех параметров шпинделя, разработана и проверена длительным опытом. Процесс ремонта шпинделей, выполняемого SKF, охватывает все необходимые этапы:

$\rightarrow$ общий визуальный осмотр;

$\rightarrow$ входной контроль и тестирование (опция);

$\rightarrow$ проверка двигателя и электрики;

$\rightarrow$ контроль привода;

$\rightarrow$ разборка шпинделя;

$\rightarrow$ проверка системы фиксации инструмента;

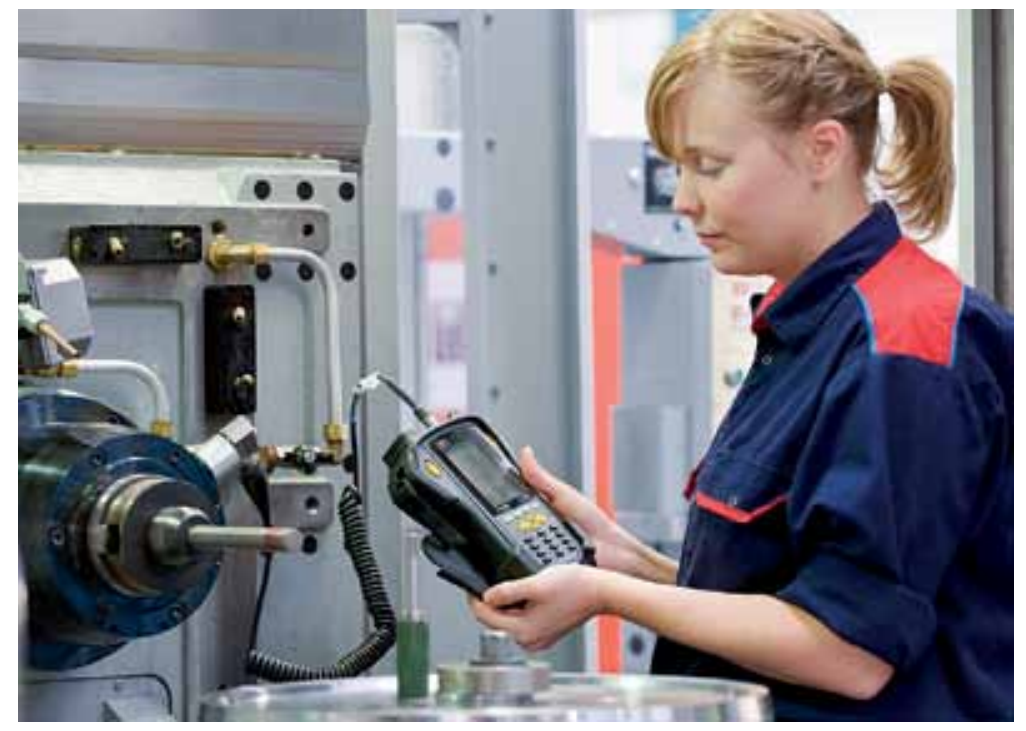

Puc. 2. Пусконаладочные работы и контроль параметров ШУ специалистом SKF 
$\rightarrow$ проверка подшипников;

$\rightarrow$ определение неисправностей;

$\rightarrow$ проверка систем охлаждения;

$\rightarrow$ проверка системы смазки;

$\rightarrow$ проверка герметичности;

$\rightarrow$ проверка посадочных мест подшипников;

$\rightarrow$ проверка вала и посадочного места инструмента;

$\rightarrow$ определение ремонтопригодности;

$\rightarrow$ балансировка вращающихся частей;

$\rightarrow$ сборка шпинделя с новыми подшипниками;

$\rightarrow$ регулировка датчика положения;

$\rightarrow$ контроль биения шпинделя;

$\rightarrow$ контроль зазора шпинделя;

$\rightarrow$ обкатка шпинделя;

$\rightarrow$ проверка дисбаланса и уровня вибрации;

$\rightarrow$ регистрация в базе данных и составление отчетной документации.

Передавая шпиндель в ремонт, клиенту важно четко понимать сроки выполнения работ, чтобы спланировать распределение человеко-часов оператора и производственной нагрузки с остановленного станка на другое оборудование. Поэтому процесс восстановления узла должен проводиться с учетом всех нюансов и включать полную дефектацию узла, обеспечивающую тщательный контроль состояния всех деталей шпинделя, на основании которого возможно объективно оценить сроки и стоимость последующего ремонта.

Для того чтобы избежать вынужденных простоев производства по причине ремонта ШУ, SKF готова предоставить сервис подменных ШУ, называемый Spindle Hotel (хранилище шпинделей). Данная концепция заключается в том, что на момент вывода в ремонт шпиндельного узла клиент получает подменный узел, что позволяет предотвратить остановку производства. Конечно, реализация такого подхода возможна только в том случае, если соглашение с клиентом было предусмотрено заблаговременно.

\section{КОНТРОЛЬ КАЧЕСТВА ПРИ ВОССТАНОВЛЕНИИ ШУ}

В связи с тем, что современная промышленность характеризуется сложной многоотраслевой структурой, а назначение продукции и процесс ее производства обуславливает применение широкого перечня станочного оборудования различных типов, перед специализированными сервисными центрами по ремонту ШУ стоит задача по адаптации оснащения для ремонта шпиндельных узлов различной конструкции. Это касается как инструмента, так и испытательных стендов, на которых производится обязательная контрольная обкатка и регистрация всех рабочих параметров восстановленного шпиндельного узла.

Полноценный контроль качества и корректная обкатка шпиндельных узлов разного типа и кон-

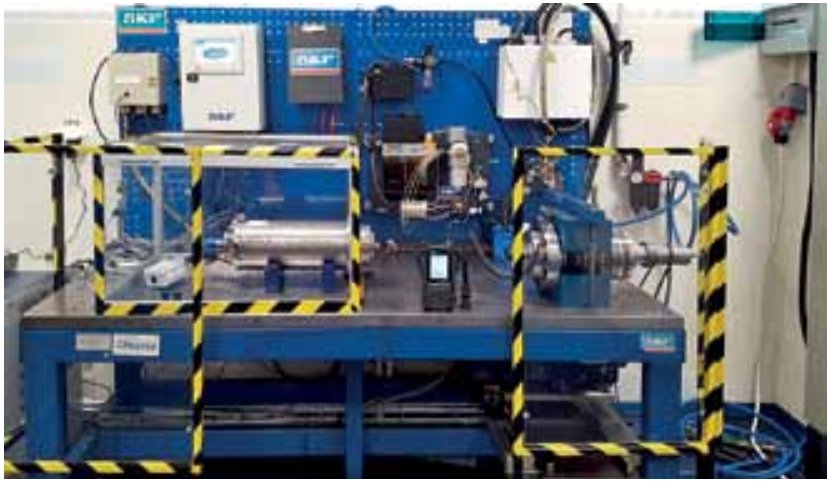

Puc. 3. Испытательный стенд SKF для обкатки ШУ

струкции на испытательном стенде возможна при наличии следующих компонентов:

$\rightarrow$ частотный преобразователь для работы с синхронными и асинхронными приводами;

$\rightarrow$ ременный привод для обкатки ШУ без собственного привода;

$\rightarrow$ многофункциональная система подачи воздушно-масляной смеси в подшипниковые опоры;

$\rightarrow$ блок подачи охлаждающей жидкости;

$\rightarrow$ система мониторинга параметров вибрации и температуры.

Финальной стадией ремонтно-восстановительных работ является регистрация выходных параметров ШУ. Полученные данные сохраняются в системе учета отремонтированных шпинделей, а на основании полученных данных по вибрации формируется «вибрационная подпись». Таким образом, у специалистов SKF есть возможность сравнения текущих параметров вибрации шпинделя на станке клиента с «вибрационной подписью», снятой при выпуске ШУ из ремонта (рис. 3).

Гарантией высокого качества восстановительного ремонта может являться использование только высококачественных комплектующих, подшипников и оборудования, а все приборы и инструменты, с помощью которых проводятся измерения, должны проходить ежегодную сертифицированную поверку.

В заключение хотелось бы отметить, что, доверяя выполнение работ по восстановлению ШУ профессионалам, вы можете быть уверены в своевременном и качественном ремонте. Это позволит вам существенно сократить частоту внеплановых простоев, обеспечивая тем самым необходимую производительность станка и качество металлообработки, а также снижение расходов на ремонт и восстановление узлов в будущем.

\section{0 «СКФ»}

тел.: +7 (495) 510-18-20, e-mail: SKF.Moscow@skf.com 